"This is the peer reviewed version of the following article: Coultas, V. (2016) Case studies of teachers' understandings of the pedagogy of classroom talk: some critical moments explored. Literacy, 50: 32-39., which has been published in final form at http://dx.doi.org/10.1111/lit.12065. This article may be used for non-commercial purposes in accordance with Wiley Terms and Conditions for Self-Archiving." 


\title{
Case Studies of teachers' understandings of the pedagogy of classroom talk: some critical moments explored. Valerie Coultas
}

\begin{abstract}
This case study research is informed by Vygotsky's view that talk is essential to organise our thoughts and extend our thinking and that, as Barnes suggested, the teacher needs to use the social situation effectively in the classroom to promote talk for learning. This article focuses on pedagogy and teachers' understandings of how talk works in the classroom, as I sought to illuminate teachers' intuitions and insights and their views of what they find challenging in organising classroom talk.
\end{abstract}

Three case studies of 'critical moments' in a lesson suggest that teacher knowledge about talk is located in concrete practices. The three teachers viewed a recorded lesson and chose a moment they defined as 'critical' because the moment helped them to learn something about the way they use talk in the classroom. They then discussed this moment with me.

These collaborative but critically evaluative processes are particularly useful for exploring and probing teachers' knowledge about talk for learning, an area of pedagogy that has proved so resistant to change over quite a long period. These three teachers suggest that such talk is becoming more marginal under the impact of performativity and the new cultural restorationist English curriculum.

Key Words: pedagogy, critical moment, talk for learning, exploratory talk, teacher knowledge, teacher self-confidence 


\section{Case studies of teachers' understandings of the pedagogy of classroom talk: some critical moments explored (5,436 words)}

'[T]teacher knowledge is embedded in concrete practices...understanding comes through the analysis of evidence drawn from practice...' (Elliot, 1994:105).

In line with Elliot's ideas about teacher knowledge, I am interested in illuminating teachers' intuitions and insights about the place of talk in learning and exploring what they have found challenging about organising classroom talk. For, while many English teachers and researchers view talk for learning as valuable, there are still challenges when it comes to actually using talk and small group learning widely in

schools. Today what I refer to as the 'talk for learning model' is now under attack as the speaking and listening strand has been downgraded in the new English Curriculum (DfE 2013 a) and GCSE exams ( 2013 b). I have suggested that the focus is returning to the elocution model of spoken language, where presentational talk and the promotion of standard English become overarching priorities, moving away from previous insights on language and learning (Coultas, 2012, 2013, 2014). This change in focus requires renewed attention to debates on classroom talk.

My current research is informed by Vygotsky's view (1978:89) that 'human learning is specifically social in nature' and that talk is essential in organising our thoughts and extending our thinking. I am suggesting that this requires the teacher to use the social situation in the classroom effectively.

\section{Case studies of critical moments for talk}

The six English teachers in this study came from a variety of backgrounds and ages and were at different stages of their careers. Two were primary teachers and four were secondary teachers. This was research with practitioners where I was seeking to improve my own knowledge of how talk works in the classroom by researching alongside English teachers whom I already knew. I was focusing on the challenges of 
talk and I needed a degree of trust between researcher and participants. The teachers had taught with me in schools or higher education or been tutored by me in teacher education and they were all interested not just in classroom talk but in 'talk for learning', where talk is seen as both a medium for learning and a skill that can be developed (Mercer 2008, Coultas, 2012).

I carried out two interviews with each of these teachers over a four year period between 2008-2012 and a group discussion with some of the teachers in 2013.In the first set of interviews I asked questions about the place of talk in learning in classrooms and in their own lives. In the second interview, the focus of this article, I wanted to stimulate a more detailed discussion of the practical challenges of talk in a particular lesson. So the teachers recorded a single teaching session where they planned to use talk for learning and then watched the video to identify a critical moment for talk. After watching the video together I then transcribed that short moment as a record with the teacher and we then analysed that moment. This moment formed the stimulus for the detailed reflection between the teacher and myself where the teachers could 'explore their handling of the case' and 'subject themselves to critique’. (Schon, 2002:7)

This idea of a critical moment for talk built on Tripp’s (1993) idea of a critical incident in teaching where a teacher look backs and analyses a key moment in professional practice to reflect on and evaluate practice in closer detail. The idea of focusing on a short video clip to stimulate reflection is also supported by Jones, (2002) as teachers are able to 'stand outside [their] practice, take stock and review it' (p 43) particularly in discussion with a critical friend.

The video recordings, therefore allowed for authentic representations of classroom practice, vignettes that reflect some of the difficulties of using talk for learning effectively. The familiar setting became a little more unfamiliar as teachers watched themselves and observed their teaching from a different perspective than is normal. A discussion took place around the recorded lesson, chosen by the teacher, and I wrote 
the short transcript as the lesson and the moment in the video was watched several times and reviewed by the teacher and I. Acting as a critical friend, I then prompted the teacher to consider a) their strengths in the lesson b) the constraints and challenges they felt were operating on them and c) what was most interesting about the moment and the lesson in an open and self- critical manner. These three prompts to aid the discussion, looking at the positive, negative and interesting features of the moment and the lesson, came from a thinking frame originally devised by De Bono (1987) and were used to probe the teachers' thinking to allow them to reflect more deeply about their practice.

The act of identifying this moment meant that the teachers were already evaluating their practice, some choosing a good moment, some choosing a moment that they found interesting or where they felt that they the student reaction had not been as they expected. But the selection provided a common reference point for researcher and teacher to focus more closely on some of the pedagogic difficulties and challenges of talk, the main research question. As Elliot (1977) suggests, improvements in practice can often come from teachers becoming aware of what they are doing rather than from others trying to control what they are doing. This concept of developing greater awareness of how talk works in the classroom both for teachers and researchers was a key idea that framed the overall approach to the research.

This idea of a critical moment for talk therefore operated on two levels. It was chosen as an approach that could probe teacher awareness of how talk works in the classroom but it was also a way of trying to make public some of the intuitions that teachers have about classroom interactions that are not always present in writing on classroom talk: an attempt, as Saunders (2012) has suggested, 'of turning teachers' expert knowledge of classroom interactions inside out'. Eyers and Richmond (1979), two English teachers reflecting on the work of the Talk Workshop at Vauxhall Manor School in London, also understood that teachers need to make records of what they are doing and use their own expertise and experiences in the classroom when looking at language to 'make sensitive inferences about an actual classroom experience, in noticing what is really going on’ (p1). 
Each critical moment, as I demonstrate below, makes some clear links between what the teachers said and what they actually did with talk and highlights very specific challenges that arise out of their unique situations. The teachers also evaluate their practice and make suggestions for what they want to do more of with talk.

\section{Peter's critical moment for talk: trying to hold onto something relevant to the pupils}

\footnotetext{
'It was a moment when I could do something entertaining and relevant'. Peter, (Field Notes, October10 ${ }^{\text {th }}$, 2011)
}

Peter is teaching a lower set Year 8 English class comprised of pupils with Special Educational Needs (SEN) and English as an Additional Language (EAL). He divides his lesson on synthesis and letter reading into two parts: the formal part where he has to teach the word synthesis and the informal part where he uses the puppet to read the letter aloud to prepare the students for a sequencing exercise, in pairs, where they will re-read the letter more independently. He chooses the beginning of the informal part of this lesson where the puppet reads the letter aloud, for his critical moment after watching the video:

'because when I bring the puppet out I could see the look of relief on my face as I slipped my hand in the glove puppet.....It was a moment where I could do something that was more entertaining and relevant' Peter, (2011).

This reading aloud exercise is an orchestrated reading of the text (Barrs and Cork, 2001) which helps to introduce the letter. This orchestrated reading works to scaffold the pupils' later attempts to complete the sequencing exercise in pairs as they try to 
re-read and reconstruct the letter. The pupils in this group are struggling readers in Year 8 who find it very difficult to read independently.

And here this teacher shows that, despite all the challenges he highlights with classroom talk in the two inner city schools he was working in during these interviews and his somewhat sceptical attitude, by using a puppet as a prop he can successfully play with the pupils and orchestrate the reading and maintain the group's attention while reading a non-fiction text, a love letter in the story, in a small class with very low reading ages. The story has been written by the teacher himself.

Peter was confident about using talk at university and in his social life and in this example he shows that he can adopt different voices in the classroom while he reads aloud and uses teacher in role. He is attempting to make learning vivid and real for these students as the topic chosen of a love letter from a boy to a girl will have an appeal for this age group, 12-13 year olds.

This is a kind of interactive or dialogic practice in a whole class setting because the teacher is in role as puppet and puppet master orchestrating the reading.

Teacher...Now I think it's time for old Macca to have an appearance today.........................Will you be able to do it? (The teacher is still talking directly to the puppet-puppet nods at the teacher) You're too nervous are you?

Pupil: Sir, can I hold him?

Teacher: Well we are all going to prompt him when he gets stuck.

What sort of things do we say to him when Macca gets stuck on his reading?

Pupil A: Take your time

Pupil B: Say the first letter

Teacher: Say the first letter 
Pupil A: Sound out- sound out

Pupil B: Calm down

Teacher: Calm down- don’t rush

(The pupils seem more engaged now, particularly the boys)

(Field notes while viewing the video, 2011)

The pupils start to interact with the puppet because they are familiar with this prop as they say 'Say the first letter', 'Sound it out, Macca' 'Take your time, Macca'. The puppet's reading difficulties mirror their reading difficulties and yet they are able to help the puppet, beginning to give advice as if they were the teacher, the expert on reading. This helps most of the pupils to engage, at some level, with the text.

This modeling of the reading prepares the sequencing exercise where the pupils will work in pairs to re-read the love letter broken up into chunks and put them back into the right order. The video of the lesson provides evidence of pupils working in pairs, often with adult support, to sequence the love letter. In response to the suggestion that some might see this lesson as having 'low expectations' of a Year 8 class in a secondary school, Peter says this suggestion does 'not really understand the problems these pupils have with reading, comprehension and formal language'. Peter, (2011)

\section{Peter's comments on the challenges of talk}

Peter suggests that abstract ideas, such as teaching synthesis, are imposed on teachers from above but that teachers' try to hang onto something that [they] feel is relevant to the children' Peter, (2011). He sees his informal or unofficial approach as a kind of subversion of the formal agenda.

He admits to being cynical about the present climate teachers find themselves in where prescription and performativity dominate. He finds it hard to take interventions 
seriously. He suggests that these are always done in 'a clumsy, insincere way that does not inspire you. It's tokenistic. The only thing that is followed through is pushing up the grades...by whatever means....' Peter, (2011)

In Peter's critical moment he shows that, despite his admitted cynicism about the dominant climate, to some extent he can interact with the pupils by choosing texts, a love letter, and teaching methods that are relevant for a teenage group with low reading ages. In the video he is not at ease when teaching the word 'synthesis' as he has been told to do. But he relaxes when he is orchestrating the reading, doing something that he has chosen to do which involves a kind of playfulness. The video also provides evidence of pupils working in pairs, sometimes with an adult, to sequence the letter. But his central difficulty is that he sees this teacher and child centred approach as subverting the official, prescriptive agenda of the school and the government. He does not feel that teachers have enough autonomy to respond to children's needs and interests. He sees current interventions in schools failing to listen, engage or inspire teachers to really develop interesting approaches to teaching.

\section{Cathy's critical moment for talk: a talk for writing challenge}

'I felt in control all the time- - there was not a moment where I felt that it was not going as planned. Apart from their responses to the final question in the plenary.' (Cathy, June $3^{\text {rd }} 2012$ )

Cathy was working as a year 4 teacher and a literacy coordinator in a primary school when she recorded this lesson. She was teaching a group of higher ability children for literacy. In Cathy's recorded lesson Cathy and I can see that she has applied her ideas about enjoying 'talking classrooms' to her practice. In the video of the lesson we can see evidence that the children have chosen a topic and then worked in jigsaw groups to read and make notes from different newspaper reports of this specific event during 
the Queen's Jubilee. Jigsaw groupings allow pupils to specialise in a topic and then report back to a home group. They have to read a report individually on their topic (for example, the events surrounding the flotilla on the Thames) and then report back to their home group to make notes on that event together.

Cathy's video therefore shows that she is able to use the social situation in the classroom effectively to construct her Jubilee jigsaw. The video demonstrates that the children in a top set are engaged with this exercise during a large part of this lesson. First they move around the room to read the newspapers and then they sit on the floor in their groups, scattered around the room, and they have some written prompts to assist them in making notes. Cathy explains that she has planned the lesson carefully beforehand.

Cathy is committed to fostering talk in classrooms as a result of a critical evaluation of her own educational experiences in school. Because Cathy feels confident about using talk in her classroom she identifies a critical moment in the plenary where the talk and the pupils’ reactions surprised her:

Teacher: Just have a quick look at the information on your sheet..... Hands up if you think that the info you have researched yourselves and the info you have gathered from your notes... who thinks they could now write an article. Or do you think that you need a few more minutes to research?

.............Hands up if you've got enough info?

(4 pupils raise their hands- mainly boys)

Teacher: More time... (5 or 6 hands go up)

(Cathy is beginning to realise that the pupils may need more time to write the article and probes the pupils further...)

Teacher: Jack, you didn’t put your hand up?

Jack: Yes, I needed more time.

(Field notes while viewing the video, 2012) 
Cathy stated that she had initially made the assumption that the research and notetaking in the jigsaw would have prepared the pupils for writing. But when she asks the pupils if they are ready, only four hands go up. Cathy has expected more pupils to be ready but the majority are not yet ready to write.

\section{Cathy's comments about the challenges of talk}

Although Cathy is surprised by how few children raise their hands to say that they feel ready to write, the video evidence shows that she uses the plenary to probe the pupils' readiness further, asking them what else they need to know to feel more confident about starting to write. She is assessing their learning in the discussion but she has perhaps initially underestimated the cognitive challenges of moving from talk and notetaking to actually writing a news report for a Year 4 class.

In discussion with me, it seems that as well as the cognitive challenge there may have been some lack of clarity over the question. Cathy said that she would address these issues and scaffold newspaper report writing in the next lesson. She stated that she would have preferred to go straight into this task but the constraints of the new ability groupings for literacy interfered as part of the group had to return to their normal mixed ability class. This last statement is interesting because, at the first interview stage of this study, there was no direct evidence of the constraints of exams and performativity on Cathy's teaching. But the setting for literacy, with pupil groupings based on judgements of ability, has interrupted the flow of her lessons and this is a new adjustment the school has made in order to raise standards in literacy. Cathy (2012) is slightly ambivalent about these new ability groupings and comments that 'I'm not an entire fan of the sets but I have seen some benefits'.

To sum up on the topic of teacher understanding of the challenges of talk in classrooms we see an effective use of the jigsaw arrangement for group work to promote independent reading and collaborative note taking about the Queen's Jubilee celebrations. But questioning at the end reveals that the pupils will need more support to move from talk and note taking to writing to be able to complete their own 
newspaper article. Constraints imposed by the new setting for literacy mean that the writing task will have to wait until the next lesson.

Cathy suggested that she liked to interact with a group as they are doing the task and that if she stayed with a group the children, they would begin to really talk with her in a more open way. This would have allowed her to ask one group the question she asked the whole group at the end and she would then perhaps have been able to anticipate the difficulties they might have had in writing the article. Cathy explained that she had to give some of her attention to the videoing of the lesson, where she had to assist the Teaching Assistant, and this may have interfered a little with her normal practice.

But the critical moment discussion allowed Cathy to gain more understanding of the need to identify the precise steps in moving from talk and note taking to writing. This is a key dilemma for English teachers and one that Cathy certainly encountered in this critical moment in her lesson. Cathy has become more aware of what she is doing when moving from talk to writing in her lessons. She will perhaps be able to anticipate the stages in this process of moving from talk to writing in the future.

\section{Jean's critical moment for talk: exams and independent learning}

'Does exam pressure mean that I sound patronising, talking lower and slower and that I do not encourage enough independent learning... there's a notion of a 1920s teacher there. I was not learning from them in the way that I might do in the top sets?' Jean (Field notes, June $6^{\text {th }}, 2012$ )

Jean was working as an English and Media teacher in a secondary school when she recorded her lesson. In Jean's critical moment we see two pupils in a $6^{\text {th }}$ form English GCSE retake group using exploratory talk to write a letter to the Head Teacher about school uniforms. But in her reflections Jean is concerned about how she addresses the whole group and the exam pressures on her and the pupils. I focus first on the chosen critical moment and then discuss her understanding of her challenges. 
The task set is writing a persuasive letter to prepare the students for the GCSE English exam the next day. The video of the critical moment provides evidence of the two pupils being involved in the task and contributing to the writing through exploratory talk.

\section{(Pupils $L$ and $K$ are engaged with the task making suggestions, refining and clarifying their ideas...)}

Pupil K: It makes you look more presentable....school

Pupil L: No---it makes your school look better

Pupil K: Yeah....

Pupil L: Argue... well we're in the sixth form. We shouldn't really need school uniform.

Pupil K: So you're saying sixth form is separate to the main school....

(Field notes while viewing the video, 2012)

The pupils are working together, completing each other's sentences and rehearsing ideas for the letter. One pupil does more writing than the other. One of the pupils initiates an exchange with the teacher and tries out a sentence he wants to use in his letter suggesting he might ask the head teacher to 'scrap' the uniform:

Pupil L: So can I put 'I am writing to inform you that I don't like the school uniform ...can you please scrap them?

Teacher: What do you think of that K? (K shakes his head giggling)

Teacher: Sounds a bit rough (lowered voice- touch of humour in response not a reprimand- teacher seems to be implying that a game is being played here and that they know that this is not right. Both boys are smiling)

You actually want her to change the uniform don't you? (A reminder of purpose and audience here) 


\section{Pupil K: Yeah...}

Teacher: What sort of tone do you need to have?

Pupil K: Um.....sophisticated...

Teacher: Sophisticated—what else?

Pupil L: Informal

Pupil K: No-formal, formal!

(Field notes while viewing the video, 2012)

There is a sense of playfulness and banter in the conversation and Jean uses a colloquial phrase in response 'sounds a bit rough'. The teacher is participating in the playful and colloquial aspect of exploratory talk but also clarifying the audience the pupils should be addressing in the writing task and the register that they should use. The boys are smiling and the teacher has lowered her voice. Perhaps all the participants enjoy the irony here? The warm tone of the exchange, even more than the precise words used, emphasises the positive relationship between the pupils and the teacher. They can ask and they can play and they can learn and incorporate the teacher's language when they build on the word 'sophisticated' and use the word 'formal' later in the conversation because there is an ethos of trust and respect.

Jean's critical moment is a short but quite powerful example of why exploratory and collaborative talk in small groups allows for more pupil input as it gives pupils opportunities to play with and interrogate language and clarify thinking. This is shown by the way the pupils engage with each other: the more confident writer Pupil $\mathrm{L}$ is writing but the other pupil helps shape the writing through talk and by the way they engage with the teacher.

Jean has had quite a positive experience of talk in her own family and community and was able to develop her self-confidence with talk, to some extent, in the early stages 
of her primary school and in her secondary school. This background influences her desire to allow for pupil self-expression. Her reflections in her two interviews with me suggest that she has allowed the pupils to be more expressive as she has become more established as a teacher in this school. She is using small group exploratory talk successfully in a $6^{\text {th }}$ form retake group.

\section{Jean's comments: the challenges of talk}

Jean identifies her challenge with this group, which has many pupils with English as an Additional Language EAL, despite the example of effective paired talk, as being very aware of the pressures on the pupils from their families to make the grade and get the $\mathrm{C}$. She knows that some of them, who are quite new to English, are going to find this very difficult, especially as English coursework has now been abolished.

She feels that these family aspirations put pressure on her to just 'get the job done' and is anxious that 'I am taking them all with me' in whole class discussions. Importantly, this exam and parental pressure means she feels that she has to abandon some of the spontaneity she uses with the higher sets. When looking at an earlier part of the video she says 'I sound patronising, talking lower and slower and that I do not encourage independent learning in the way that I might do in the top sets.'(Jean, 2012).

Jean's challenge is to feel that although she has worked well with a small group she may still be patronising the lower sets in whole class discussions because of the pressure to 'get the job done' and get them through the exam. From looking at her teaching on video, she becomes more aware that she wants to be more mobile and open to learning from her students in whole class discussion as well as through small group interactions. She, like Cathy, sees that by interacting more with one group and being more mobile she may be able to do this. But she also wants to 'show that she is there for all' and to be able to encourage more independent thinking in whole class discussions in her lower sets (Jean, 2012).

\section{Summary: what do these critical moments tell us about how talk works in the classroom and its challenges from the teacher's point of view?}


In these critical moments of three lessons, all the teachers have promoted some form of pupil-to-pupil or pupil-to-teacher interactions using talk for learning in their chosen lesson. Peter's interactive reading aloud in role as a puppet encouraged interaction from the pupils with special needs and EAL in his Year 8 lower set English class and prepared the sequencing activity in pairs that followed this reading. Both the reading aloud and the sequencing activity allowed the pupils to engage in some form of dialogue with each other and the two other adults in the room. Cathy's jigsaw activity in groups has involved her year 4 pupils in taking notes and summarising information from newspapers. Jean's lesson with her sixth form pupils demonstrated how exploratory talk in pairs allowed pupils to think aloud to plan and begin to write a persuasive letter. This represents evidence of teachers attempting to use 'learning talk' effectively in the classroom.

The specific challenges they highlight in these examples are often influenced by contextual and psychological or affective factors.

The contextual factors relate to how the teachers view the contexts they are working in. My prompting of the teachers to talk about the constraints that they faced, allowed the teachers to comment on the institutional factors that mediated their work in classrooms. Cathy, Peter and Jean are, in different ways, all very worried about performativity cultures inhibiting their flexibility with talk and independent learning in the classroom. Cathy's discussion of her critical moment focuses on how to use talk for writing to prepare younger pupils for writing a newspaper article but the setting for literacy does not allow her to adapt her lesson on the spot as she has to break up the group so that the pupils can return to their normal Year 4 mixed ability class for the rest of their lessons.

Peter is concerned about having teaching approaches imposed on him from above and how to 'try to hang onto something that is relevant to the pupils' (2011) with SEN and EAL, in such a prescriptive era. Peter saw his informal or unofficial approach as a kind of subversion on the formal agenda. He found school improvement interventions problematic today suggesting that they are always done in 'a clumsy, insincere way that does not inspire you....the only thing that is followed through is 
pushing up the grades...by whatever means' (2011). Jean is also concerned about sounding patronising in whole class discussions and how to encourage independent learning in her sixth form English retake group who struggle to gain a grade $\mathrm{C}$ in the GCSE exam.

The teachers thus suggest that the standards rhetoric, that is highly outcomes and exam oriented, puts pressure on teachers to use more traditional methods of teacher talk, reinforcing didactic methods to drill students to get the grades. What the teachers' insights suggest is that this exam-focused approach has become more dominant rather than an approach that encourages teachers to think about how students learn and plan for pupil-led interactions, discovery and problem solving approaches and learning talk. For example, Jean in her first interview states that in her view in English departments 'talk is not a priority at the moment' (2010). Cathy (2013), in the discussion group, also points to the marginalisation of talk for learning suggesting that if you had a positive view of talk as a teacher it kind of came naturally but, in the test culture, if you did not have this view there was no encouragement to use talk for learning anymore. The new English Curriculum (DfE, 2013), as mentioned earlier, further reinforces traditional and didactic approaches to pedagogy and spoken language rather than valuing home and community literacy practices as the Bullock Report (1975) suggested. These teachers' insights about talk for learning are therefore at odds with the ever moving forwards rhetoric of the school improvement discourse (Wrigley, 2002, Jones, 2011, Coultas, 2013).

The more psychological and affective factors that come into play are to do with the teachers feeling in control of their teaching, feeling committed to what they are doing, having agency in the classroom and feeling relaxed and comfortable. Here we touch on teachers' tacit knowledge (Holbrook,1979) understanding that teaching is a creative and , to some extent, performance based profession and that creative acts are shot through with strong personal feelings of passion, control and commitment and that these passions can discover 'truths'. The ethos of the classroom affects both pupils and teachers. Alexander (2008), admitting that achieving a dialogic classroom 
is no easy task, also suggests that it might be a first step to concentrate 'on getting the ethos, dynamics and the affective climate right' (p110).

Peter, the more experienced teacher, highlights these affective aspects particularly in both interviews. Perhaps this is because, as he states in his first interview, he believes that teachers have less control over and less commitment to what they teach now and feel more alienated in contrast to his earlier years in teaching. In his discussion of his critical moment he feels that his choice of text and method of reading aloud engages the pupils in the lesson in a way in which the imposed agenda of 'teaching synthesis' in an abstract way does not. But Cathy also talks about where she feels in control and where she feels less so. 'I felt in control all the time- there was not a moment where I felt that it was not going as planned. Apart from their responses to the final question in the plenary.'(2012) She has anticipated that more of this higher set would be ready to write and describes herself as feeling less in control when their responses are not what she expected.

The detailed reflections in the critical moments, a result of the close discussion of the video, allowed teachers to highlight their understandings of what they are doing well and discuss their constraints and express some of their inner thoughts, their state of mind in the classroom. But the teachers were not complacent and began to think about how to use talk more effectively such as interacting more with the small groups or the larger group, feeling that they need to be more free to use their own knowledge of what works with the students, needing wider support and understanding of the pedagogy of language and learning in the department or school for the talk for learning model to work more effectively.

These responses from the teachers endorse the view of Elliot (1977) that making teachers more aware of their practice can facilitate critical reflection. I would suggest that these collaborative but critically reflective processes are particularly useful for exploring teachers' knowledge about talk, an area of pedagogy that is often not fully understood, has proved so resistant to change over quite a long period and is now under attack. 


\section{Bibliography}

Alexander, R.J. (2008) 'Culture, Dialogue and Learning' in Mercer, N and Hodgkinson, S (Eds) Exploring Talk in School London: Sage pp 91-115

Barnes, D (2008) Exploratory Talk for Learning in Mercer, N and Hodkinson, E (Eds) Exploratory Talk in School London: Sage pp 1-17

Barrs, M and Cork, V (2001) The Reader in the Writer Case Studies in Children's Writing London: CLPE

Bullock, A (1975) A language for life: report of the Committee of Inquiry appointed by the Secretary of State for Education and Science under the chairman ship of Sir Allan Bullock London: Her Majesty’s Stationery Office (HMSO)

Coultas, V (2012) Let's Talk about Talk for Learning: Gove's Standards on Spoken English October 2012 EnglishDramaMedia Magazine NATE pp 58-60

Coultas, V (2013) English for the Few or English for the Many? Ainley, P and Allen, M (Eds) Education Beyond the Coalition -reclaiming the agenda London: Radicaled

December 2013

Coultas, V (2015) Revisiting debates on oracy: classroom talk, moving towards a democratic pedagogy? Changing English Studies in Culture and Education Volume 22, Issue 1, 2015 available at http://www.tandfonline.com/eprint/TVth2HX4yTKEhDpusvMP/full accessed 2nd May 2015

DfE (2013a) Programme of Study for English Key Stage Four

http://media.education.gov.uk/assets/files/pdf/e/english\%20\%20key\%20stage\%204\%2005-02-13.pdf accessed July 26th 2013

DfE (2013b) GCSE English Language

http://media.education.gov.uk/assets/files/pdf/e/english\%20\%20key\%20stage\%204\%2005- 
0213.pdfhttps://www.gov.uk/government/uploads/system/uploads/attachment_data/fil e/206143/GCSE_English_Language_final.pdf

accessed June 30th 2013

De Bono, E (1987) Six Thinking Hats Harmondsworth: Penguin

Elliot, J (1977) Conceptualising relations between research/evaluation procedures and in-service Teacher education British Journal of In-Service Education, 4 (1/2)

Elliot, J (1994) Research on Teacher’s Knowledge and Action Research Educational Action Research 2 pp. 102-105

Eyers, S and Richmond, J (1982) ‘Talk Workshop Group: An Introductory Paper’ in Talk Workshop Group 1982 Becoming Our Own Experts The Vauxhall Papers: studies in language and learning made by the Talk Workshop Group at Vauxhall Manor School 1974-1979 London: Inner London Education Authority (ILEA) English Centre

Goodson, I (1992) Studying Teachers’ Lives London: Routledge

Holbrook, D (1979) English for Meaning. Windsor: NFER

Jones, L (2002) Using Videos to investigate speaking and listening O. McNamara (Ed) Becoming an Evidence Based practitioner A framework for teacher researchers London: Routledge Falmer

Jones, K (2011) Schooling in Western Europe: The New Order and its adversaries Goldsmith’s University Inaugural Lecture March $2^{\text {nd }} 2011$

Mercer, N and Hodgkinson, S (2008) Exploring Talk in School London: Sage

Saunders, L (2012) Speech to Kingston University School of Education Research Conference July $12^{\text {th }} 2012$

Tripp, D (1993) Critical Incidents in Teaching Abingdon, Oxon, Routledge 
Vygotsky, L.S (1978) Mind in Society: The Development of Higher Psychological Processes Cambridge MA: Harvard University Press

Wrigley, T (2002) Class, Culture and Curriculum: critical issues for school improvement Education and Social Justice 4 (3) Trentham Books 8-21 